\title{
Special Issue "Selected Papers from the 5nd Edition of Global Conference on Catalysis, Chemical Engineering and Technology (CAT 2019)"
}

\author{
Stanislaw Dzwigaj ${ }^{1, *(1)}$ and Arthur Nozik ${ }^{2}$ \\ 1 Laboratoire de Réactivité de Surface, CNRS, UMR 7197 Campus Pierre et Marie Curie, Sorbonne Université, 4, \\ Place Jussieu, 75252 Paris, France \\ 2 Department of Chemistry and Biochemistry, University of Colorado, Boulder, CO 80309, USA; \\ arthur.nozik@colorado.edu \\ * Correspondence: stanislaw.dzwigaj@sorbonne-universite.fr
}

Citation: Dzwigaj, S.; Nozik, A. Special Issue "Selected Papers from the 5nd Edition of Global Conference on Catalysis, Chemical Engineering and Technology (CAT 2019)". Catalysts 2021, 11, 65. https://doi.org/ 10.3390/catal11010065

Received: 29 December 2020 Accepted: 30 December 2020 Published: 5 January 2021

Publisher's Note: MDPI stays neutral with regard to jurisdictional clai$\mathrm{ms}$ in published maps and institutional affiliations.

Copyright: (C) 2021 by the authors. Licensee MDPI, Basel, Switzerland. This article is an open access article distributed under the terms and conditions of the Creative Commons Attribution (CC BY) license (https:// creativecommons.org/licenses/by/ $4.0 /)$.
The present Special Issue concerns the papers which have been presented at the fifth edition of the Global Conference on Catalysis, Chemical Engineering \& Technology (CAT 2019) that promote linkage of the catalytic science, engineering and technology. The topics of the conference have covered various aspects of catalysis in all of its diversity, as well as the areas of the chemical engineering and technology.

Meloni et al. [1] have presented a short review on Ni based catalysts and related engineering issues for methane steam reforming. The steam reforming of methane is the most used process for production of hydrogen, an important raw material in chemical industries. In methane steam reforming process, the use of a catalyst is mandatory. Nibased catalysts give an acceptable high activity when compared to precious metal-based catalysts appeared much more expensive. The high activity and the low cost made Ni catalysts have been widely studied by the scientific community in methane steam reforming. Advancements in catalysis technologies and methods have improved the state of methane steam reforming, in particular the synthesis methods of nano-sized particles, including impregnation, co-sputtering, and chemical vapor deposition, allow for highly dispersed dopants and high activity. The researchers showed that the addition of metallic or bimetallic species to a Ni based catalyst can improve selectivity, durability, and activity, thus limiting the typical problems of the methane steam reforming, including coke formation, active oxidation, sintering, and segregation. This review evidenced that most common materials used as supports or support dopants are $\mathrm{CeO}_{2}, \mathrm{ZrO}_{2}$, and their mixed oxides, since their high oxygen storage capacity and redox properties lead to efficient coke resistance, which makes these materials advantageous over conventionally used $\mathrm{Al}_{2} \mathrm{O}_{3}$ or $\mathrm{MgAl}_{2} \mathrm{O}_{4}$. The complexity of the traditional steam reforming process involving many very different operation units is optimized for the industrial scale, limiting the possibility to realize process intensification. In the last years, the scientific research focused on the development of innovative hydrogen production systems as well as on the optimization of the conventional processes and, in this sense, the catalyst has a fundamental role. The steam reforming catalysts must meet stringent requirements, such as high activity, reasonable life, good heat transfer, low pressure drop, high thermal stability, and excellent mechanical strength. In addition, the necessity of reducing the costs made the development of methane steam reforming processes operating at low temperature mandatory, so avoiding, for example, the use of special steel alloy. The development of new catalysts with well-defined properties is fundamental in order to reach this objective: in fact, the catalyst must activate methane at low temperature, it must drive its conversion up to equilibrium values at short contact times and, in addition, it must be resistant to deactivation factors including carbon formation, which is favored at low temperature, and preferential oxidation, which occurs at low temperature mainly for Ni catalysts. The objective of a low temperature methane 
steam reforming can be reached by contemporarily separating a product, such as $\mathrm{H}_{2}$, by means of membrane reactors, or $\mathrm{CO}_{2}$, as in the case of sorption enhanced steam reforming process, since methane steam reforming at low reaction temperature results in low $\mathrm{CH}_{4}$ conversions due to thermodynamic limitations.

Chalupka et al. [2] have studied the influence of the preparation procedure and activation conditions such as reduction temperature and reducing medium: pure hydrogen $\left(100 \% \mathrm{H}_{2}\right)$ or hydrogen-argon mixture $\left(5 \% \mathrm{H}_{2}-95 \% \mathrm{Ar}\right)$ on the activity of Co-containing BEA zeolites in Fischer-Tropsch synthesis. In this work, a series of CoBEA zeolites were obtained by a conventional wet impregnation (CO5.0 AlBEA) and a two-step postsynthesis preparation procedure involving dealumination and impregnation steps ( $\mathrm{CO}_{5.0} \mathrm{SiBEA}$ ). Both types of zeolites were calcined in air at $500{ }^{\circ} \mathrm{C}$ for $3 \mathrm{~h}$ and then reduced at 500, 800 and $900{ }^{\circ} \mathrm{C}$ for $1 \mathrm{~h}$ in $100 \% \mathrm{H}_{2}$ and in $5 \% \mathrm{H}_{2}-95 \%$ Ar mixture flow. The obtained RedC-Co5.0 AlBEA and Red-C-Co5.0 SiBEA catalysts with various physicochemical properties were tested in Fischer-Tropsch reaction. Among the studied catalysts, Red-C-CO ${ }_{5.0} \mathrm{SiBEA}$ reduced at $500{ }^{\circ} \mathrm{C}$ in pure hydrogen was the most active, presenting selectivity to liquid products of $91 \%$ containing mainly $C_{7}-C_{16}$ n-alkanes and isoalkanes as well as small amount of olefins, with CO conversion of about $11 \%$. The Red-C-Co ${ }_{5.0}$ AlBEA catalysts were not active in the Fischer-Tropsch synthesis. It showed that removal of aluminum from the BEA zeolite in the first step of postsynthesis preparation procedure played a key role in the preparation of efficient catalysts for Fischer-Tropsch synthesis. An increase of the reduction temperature from 500 to 800 and $900{ }^{\circ} \mathrm{C}$ resulted in two times lower $\mathrm{CO}$ conversion and a drop of the selectivity towards liquid products (up to $62-88 \%$ ). The identified main liquid products were n-alkanes and isoalkanes. The higher activity of

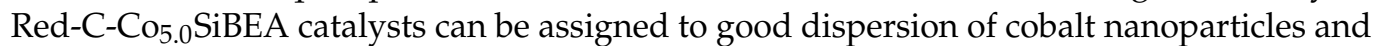
thus a smaller cobalt nanoparticles size than in the case of Red-C-Co5.0AlBEA catalyst.

Bozbag et al. [3] have developed a unified transient kinetic model which can predict the adsorption, desorption and oxidation kinetics of $\mathrm{NH}_{3}$ over hydrothermally aged $\mathrm{Cu}$ chabazite. The model considers the variation of fractional coverages of $\mathrm{NH}_{3}$ storage sites due to hydrothermal aging. In order to determine the fractional coverage of these sites, the catalyst was aged for various times at a certain temperature followed by $\mathrm{NH}_{3}$ adsorption, desorption and temperature-programmed desorption (TPD) experiments. TPD profiles were deconvoluted mainly into three peaks with centres at 317,456 and $526{ }^{\circ} \mathrm{C}$, respectively. Hydrothermal aging resulted in the progressive increase in the intensity of the peak at $317^{\circ} \mathrm{C}$ and decrease in the intensity of the peaks at 456 and $526^{\circ} \mathrm{C}$, along with decreased $\mathrm{NH}_{3}$ oxidation at high temperatures. A model for hydrothermal aging kinetics of the fractional coverage of storage sites was developed using three reactions with appropriate rate expressions with parameters regressed from experimental data. The model was then incorporated into a multi-site kinetic model for the degreened $\mathrm{Cu}$-chabazite by the addition of aging reactions on each storage site. The effects of both aging time and temperature on the kinetics $\mathrm{NH}_{3}$ adsorption, desorption and oxidation were successfully predicted in the $155-540{ }^{\circ} \mathrm{C}$ range. This study is the first step towards the development of a hydrothermal aging-unified kinetic model of $\mathrm{NH}_{3}$-selective catalytic reduction over $\mathrm{Cu}$-chabazite.

Boyadjian et al. [4] have investigated the molybdena-promoted $\mathrm{Li} / \mathrm{MgO}$ as a catalyst for the oxidative conversion of $n$-hexane. The structure of the catalysts has been investigated with X-ray Diffraction (XRD) and Raman spectroscopy. The $\mathrm{MoO}_{3} / \mathrm{Li} / \mathrm{MgO}$ catalyst contained three types of molybdena-containing species, the presence of which has been depended on molybdena loading. At low $\mathrm{Mo} / \mathrm{Li}$ ratios (i) isolated dispersed $\left[\mathrm{MoO}_{4}\right]^{2-}$ anionic species has been observed. At high $\mathrm{Mo} / \mathrm{Li}$ ratios, the formation of crystalline lithium molybdate phases such as (ii) monomeric $\mathrm{Li}_{2} \mathrm{MoO}_{4}$ and tentatively (iii) polymeric $\mathrm{Li}_{2} \mathrm{Mo}_{4} \mathrm{O}_{13}$ have been concluded. The presence of these lithium molybdates diminished the formation of $\mathrm{Li}_{2} \mathrm{CO}_{3}$ in the catalyst. Subsequently, the catalyst maintained high surface area and stability with time-on-stream during oxidative conversion. Molybdena loading as low as $0.5 \mathrm{wt} \%$ has been sufficient to induce these improvements, maintaining the non-redox characteristics of the catalyst, whereas higher loadings enhanced deep oxidation 
and oxidative dehydrogenation reactions. Promoting a $\mathrm{Li} / \mathrm{MgO}$ catalyst with $0.5 \mathrm{wt} \%$ $\mathrm{MoO}_{3}$ has been thus efficient for selective conversion of $\mathrm{n}$-hexane to alkenes, giving alkene yield up to $24 \%$ as well as good stability.

Sadek et al. [5] have studied the influence of nickel introduction on the catalytic performance of cobalt microporous and mesoporous Beta zeolite catalysts in FischerTropsch Synthesis. Catalysts containing $3 \mathrm{wt} \%$ of nickel and $10 \mathrm{wt} \%$ of cobalt were prepared by co-impregnation and sequential impregnation and comprehensively characterized by XRD, XPS, $\mathrm{NH}_{3}-\mathrm{TPD}, \mathrm{TPR}-\mathrm{H}_{2}$ and TEM EDX techniques. Neither the dealumination of Beta zeolite nor the incorporation of $\mathrm{Co}$ and $\mathrm{Ni}$ affected its structure, as shown by XRD and BET investigations. The presence of nickel results in the decrease in the temperature of the cobalt oxide reduction, evidenced by TPR- $\mathrm{H}_{2}$ and the increase of $\mathrm{CO}$ conversion. Among all the tested catalysts, the best catalytic properties in FTS showed that based on microporous dealuminated zeolites with a very high CO conversion, near $100 \%$, and selectivity to liquid products of about $75 \%$. In case of dealuminated samples, the presence of Ni decreased the selectivity to liquid products. All catalysts under study showed high resistance to deactivation during the whole time of synthesis $(24 \mathrm{~h})$. The very high stability of nickel-cobalt based Beta catalysts was probably due to the hydrogen spillover from metallic nickel particles to cobalt oxides, which decreased re-oxidation of the active phase, sintering and the creation of the carbon on the catalyst surface. Moreover, as reported in this paper, the presence of $\mathrm{Ni}$ on the surface of cobalt-based Beta catalysts could obstruct the formation of graphitic carbon and, in consequence, delay the deactivation of the catalyst.

Matienzo et al. [6] have investigated the $\mathrm{IrO} 2$ and $\mathrm{NiO}$ thin films prepared by atomic layer deposition for oxygen evolution reaction. Atomic layer deposition is a special type of chemical vapor deposition technique that can grow uniformed thin films on a substrate through alternate self-limiting surface reactions. Recently, the application of these thin film materials to catalytic systems has begun to attract much attention, and the capacity to deposit these catalytic films in a highly controlled manner continues to gain importance. In this study, $\mathrm{IrO}_{2}$ and $\mathrm{NiO}$ thin films (approximately 25 to $60 \mathrm{~nm}$ ) were deposited on industrial Ni expanded mesh as an anode for alkaline water electrolysis. Different atomic layer deposition operating parameters such as the total number of deposition cycles, sublimation and deposition temperatures, and precursors pulse and purge lengths were varied to determine their effects on the structure and the electrochemical performance of the thin film materials. Results from the electrochemical tests $\left(6 \mathrm{M} \mathrm{KOH}, 80{ }^{\circ} \mathrm{C}\right.$, up to $10 \mathrm{kA} / \mathrm{m}^{2}$ ) showed the catalytic activity of the samples. Oxygen overpotential values $\left(\eta \mathrm{O}_{2}\right)$ were 20 to $60 \mathrm{mV}$ lower than the bare $\mathrm{Ni}$ expanded mesh. In summary, the study has demonstrated the feasibility of using the atomic layer deposition technique to deposit uniformed and electroactive thin films on industrial metallic substrates as anodes for alkaline water electrolysis.

Jedrzak et al. [7] have investigated $\mathrm{Ga}_{2} \mathrm{O}_{3} /$ lignin and $\mathrm{ZrO}_{2} /$ lignin hybrid materials obtained and used as supports for the adsorption of the enzyme glucose oxidase. A biosensor system based on the hybrid supports was then designed to determine the concentration of glucose in various solutions. The obtained bioinspired platforms were analyzed to determine chemical and physical properties of the support structures. A determination was made of the effectiveness of the proposed method of immobilization and the quality of operation of the constructed glucose biosensor in electrochemical tests. To characterize the materials, Fourier transform infrared spectroscopy, transmission electron microscopy, scanning electron microscopy, X-ray diffraction, thermogravimetric analysis, electrokinetic (zeta) potential measurements, atomic force microscopy, particle size measurements (NIBS technique), and elemental analysis were used. In further research, glucose oxidase (GOx) was immobilized on the surface of the obtained functional $\mathrm{Ga}_{2} \mathrm{O}_{3} /$ lignin and $\mathrm{ZrO}_{2} /$ lignin biomaterials. The best immobilization capacities-24.7 and $27.1 \mathrm{mg} \mathrm{g}^{-1}$ for $\mathrm{Ga}_{2} \mathrm{O}_{3} /$ lignin and $\mathrm{ZrO}_{2}$ /lignin, respectively-were achieved after a $24 \mathrm{~h}$ immobilization process. The $\mathrm{Ga}_{2} \mathrm{O}_{3} / \mathrm{Lig} / \mathrm{GOx}$ and $\mathrm{ZrO}_{2} / \mathrm{Lig} / \mathrm{GOx}$ systems were used for the construction of electro- 
chemical biosensor systems, in a dedicated carbon paste electrode with the addition of graphite and ferrocene.

Usman et al. [8] have studied propene adsorption-chemisorption behaviors on $\mathrm{H}$ SAPO-34 zeolite catalysts at different temperatures. Propene is an important synthetic industrial product predominantly formed by a methanol-to-olefins catalytic process. Propene is known to form oligomers on zeolite catalysts, and parameters to separate it from mixtures and its diffusion properties are difficult to measure. In the paper, the authors explored the adsorption-chemisorption behavior of propene by choosing SAPO-34 zeolites with three different degrees of acidity at various adsorption temperatures in an ultra-high-vacuum adsorption system. H-SAPO-34 zeolites were prepared by a hydrothermal method, and their structural, morphological, and acidic properties were investigated by XRD, SEM, EDX, and temperature-programmed desorption of ammonia $\left(\mathrm{NH}_{3}-\mathrm{TPD}\right)$ analysis techniques. The XRD analysis revealed the highly crystalline structure which posses cubic morphology as confirmed by SEM images. The analysis of adsorption of propene on SAPO-34 revealed that a chemical reaction (chemisorption) was observed between zeolite and propene at room temperature when the concentration of acidic sites was high $(0.158 \mathrm{mmol} / \mathrm{g})$. The reaction was negligible when the concentration of the acidic sites was low $(0.1 \mathrm{mmol} / \mathrm{g})$ at room temperature. However, the propene showed no reactivity with the highly acidic SAPO-34 at low temperatures, i.e., $-56{ }^{\circ} \mathrm{C}$ (using octane + dry ice), $-20^{\circ} \mathrm{C}$ (using $\mathrm{NaCl}+$ ice), and $0{ }^{\circ} \mathrm{C}$ (using ice + water). In general, low-temperature conditions were found to be helpful in inhibiting the chemisorption of propene on the highly acidic H-SAPO-34 catalysts, which can facilitate propene separation and allow for reliable monitoring of kinetic parameters.

Finally, we would like to express our sincerest thanks to all the authors for their valuable contributions and the editorial team of Catalysts for their kind support, without which the publication of this Special issue would not have been possible.

Funding: There is no external funding.

Institutional Review Board Statement: Not applicable.

Informed Consent Statement: Not applicable.

Conflicts of Interest: The authors declare no conflict of interest.

\section{References}

1. Meloni, E.; Martino, M.; Palma, V. A short review on Ni based catalysts and related engineering issues for methane steam reforming. Catalysts 2020, 10, 352. [CrossRef]

2. Chalupka, K.A.; Grams, J.; Mierczynski, P.; Szynkowska, M.I.; Rynkowski, J.; Onfroy, T.; Casale, S.; Dzwigaj, S. The impact of reduction temperature and nanoparticles size on the catalytic activity of cobalt-containing BEA zeolite in Fischer-Tropsch synthesis. Catalysts 2020, 10, 553. [CrossRef]

3. Bozbag, S.E.; Sanli, D.; Ozener, B.; Hisar, G.; Erkey, C. An aging model of $\mathrm{NH}_{3}$ storage sites for predicting kinetics of $\mathrm{NH}_{3}$ adsorption, desorption and oxidation over hydrothermally aged Cu-Chabazite. Catalysts 2020, 10, 411. [CrossRef]

4. Boyadjian, C.; Lefferts, L. Promoting Li/MgO catalyst with molybdenum oxide for oxidative conversion of n-hexane. Catalysts 2020, 10, 354. [CrossRef]

5. Sadek, R.; Chalupka, K.A.; Mierczynski, P.; Maniukiewicz, W.; Rynkowski, J.; Gurgul, J.; Lason-Rydel, M.; Casale, S.; Brouri, D.; Dzwigaj, S. The Catalytic Performance of Ni-Co/Beta Zeolite Catalysts in Fischer-Tropsch Synthesis. Catalysts 2020, 10, 112. [CrossRef]

6. Matienzo, D.J.D.; Settipani, D.; Instuli, E.; Kallo, T. Active $\mathrm{IrO}_{2}$ and $\mathrm{NiO}$ thin films prepared by atomic layer deposition for oxygen evolution reaction. Catalysts 2020, 10, 92. [CrossRef]

7. Jedrzak, A.; Rebis, T.; Kuznowicz, M.; Kolodziejczak-Radzinska, A.; Zdarta, J.; Piasecki, A.; Jesionowski, T. Advanced $\mathrm{Ga}_{2} \mathrm{O}_{3}$ /Lignin and $\mathrm{ZrO}_{2}$ /Lignin hybrid microplatforms for glucose oxidase immobilization: Evaluation of biosensing properties by catalytic glucose oxidation. Catalysts 2020, 10, 1044. [CrossRef]

8. Usman, M.; Zhu, J.; Chuiyang, K.; Arslan, M.T.; Khan, A.; Galadima, A.; Muraza, O.; Khan, I.; Helai, A.; Al-Maythalony, B.A.; et al. Propene adsorption-chemisorption behaviors on H-SAPO-34 zeolite catalysts at different temperatures. Catalysts 2020, 10, 919. [CrossRef] 